\title{
An amazing come-back: A counterfactual imperfective in
}

\section{Russian}

Abstract.

The paper shows how the semantically underspecified imperfective aspect in Russian becomes associated with counterfactual complete events in specific contexts, notably in chess annotations (Restan 1989), while the perfective invariably denotes factual complete events. The counterfactual flavour of the construction invites a comparison with more standard counterfactual conditionals, including some discussion of the imperfective and counterfactuality in French. I show that the "counterfactual imperfective" in Russian differs from ordinary counterfactual conditionals which are characterized by a semantically empty past tense. This subtle distinction leads to a further division of pragmatic labour between the form "imperfective past" (hypotheses in the past) and the "subjunctive ("by") perfective past" (hypotheses in the present/future). The analysis is couched in Bidirectional Optimality Theory (Blutner 2000), which provides an ideal framework for analyzing non-compositional formmeaning optimization and pragmatic strengthening.

\section{The first move towards the hypothetical}

One interesting feature of the Russian TAM system (tense, aspect and mood) is the role of the imperfective aspect as an aspectual default, the "elsewhere" morpheme. Competition with the perfective results in the acquisition of new territory for the imperfective in the periphery of stereotypical perfectivity. The present paper explores a case of aspectual competition which 
has repercussions on mood and tense, showing the unexpected potential of the imperfective in the division of pragmatic labour.

The point of departure for our discussion is some intriguing data ${ }^{1}$ from Russian chess annotations which suggest that the presence vs. absence of a counterfactual interpretation correlates with the imperfective and perfective aspect, respectively.

(1) После $22 . b 4^{\text {[actual chess move] }}$ белые выиграли ${ }^{\text {[pf, past] }}$ пешку.

After $22 . b 4$ white won a pawn.

(2) 22.c4 $4^{\text {[actual chess move] }}$. После $22 . b 4^{\text {[hypothetical chess move] }}$ белые выигрывали ${ }^{\text {[ipf, past] }}$ пешку.

22.c4. (Annotator's comment:) After 22.b4 white would have won a pawn.

The interpretation of (1) is simply that white won a pawn after having played the move 22.b4 in the actual chess game. The perfective aspect and past tense produce a straightforward interpretation of an indicative complete event in the past. On the other hand, the minimally different example (2) with the imperfective aspect gives rise to a rather unexpected counterfactual (irrealis) interpretation, which is problematic for any compositional theory of tense, aspect and mood. In (2), characteristic of chess annotations, the annotator comments on hypothetical possibilities in an already finished chess game, i.e. alternative moves which could have been played. It is furthermore asserted that after the hypothetical move 22.b4 white would have won a pawn. This interpretation seems to be at odds with the morphological

\footnotetext{
${ }^{1}$ I am indebted to Maria Edakina, a member of my chess club, for sharing with me her extremely good intuitions concerning the data presented in this paper. I have tested informally the reaction of Russian-speaking chess players and non-chess players on the data presented below, and the difference in comprehension is remarkable. For the first group the correct interpretation comes completely naturally, while for the latter group a certain amount of reasoning is required before they correctly interpret the imperfective as counterfactual.
} 
shape of the construction: the imperfective aspect, past tense and indicative mood corroborate to create a counterfactual interpretation.

The minimal pair above has passed largely unnoticed in the vast literature concerning Russian aspect, with the exception of Restan 1989. Nearly two decades after Restan introduced this topic in an article in Scando-Slavica, I propose to make the next move. Time is indeed ripe to move on, since Restan was content with the discovery of this new "modal imperfective" and refrained from giving any detailed analysis of the phenomenon. In the present paper, I will try to explain the role of TAM-categories in the observed data.

In order for the reader to appreciate the puzzle, a few words are necessary concerning the TAM system in Russian. Grammatical aspect (perfectivity (Pf) /imperfectivity (Ipf)) is morphologically encoded onto the verb through the use of prefixes and suffixes. Current theories of the syntax-semantics interface argue that aspect contributes to the existential closure of the event argument $e$ of the verb, an event which may be temporally included in the assertion time $t$ focussed on by the speaker (a complete event interpretation typically associated with perfective aspect) or the speaker may focus on a time interval $t$ within the time span of the event (incomplete event interpretation of imperfective aspect), as in Klein 1995. The role of tense and temporal adverbials is to locate the time interval $t$ which is needed in the aspectual inclusion relation. A possible paraphrase of the proposition thus obtained in (1) is the following:

(1') Within the time interval starting with the chess move $22 . \mathrm{b} 4$ being played (left boundary) and ending at the utterance time (right boundary), there exists an event of white winning a pawn. 
Since ( $\left(1^{\prime}\right)$ is true of the actual chess game being annotated by the speaker, the proposition is obviously true of the actual world (indicative mood). Mood is not marked morphologically on the verb in Russian, but the subjunctive particle "by" is normally required for changing the world parameter (irrealis/counterfactual mood):

(3) 22.c4 $4^{\text {[actual chess move] }}$ После $22 . b 4^{\text {[hypothetical chess move] }}$ белые выиграли ${ }^{[\mathrm{pf}, \text { past] }}$ бы ${ }^{\text {[subjunctive }}$ particle] пешку.

22.c4 After 22.b4 white would have won a pawn.

Example (3) represents the expected pattern for describing a hypothetical possibility in a game of chess. Its truth-conditions may be roughly paraphrased as follows:

(3') In all stereotypical (normal) continuations of chess games which are identical with the actual world chess game up to move 21 , but in which white deviates from the actual game and plays 22.b4 instead of 22.c4, there exists an event of white winning a pawn within the time interval starting with the chess move $22 . \mathrm{b} 4$ being played (left boundary) and ending in the infinite future.

But what, then, is the role of (2) in the grammar of Russian TAM-categories? How can we possibly explain that the combination of imperfective aspect, past tense and indicative mood gives rise to a counterfactual interpretation, which apparently could have been straightforwardly expressed by using a subjunctive, perfective past as in (3)? 


\section{En passant: Tense, aspect and mood in normal counterfactuals}

Cross-linguistically, we observe a consistent use of past tense in counterfactuals (Iatridou 2000 and Grønn \& von Stechow 2008). In Germanic and Romance languages there is a morphological difference between "one past counterfactuals" (simple past morphology, example (4) below) and "two past counterfactuals" (past perfect morphology, example (5) below). In Russian, there is only one morphological past tense form which is used both when the contrary to the facts situation takes place before the time of utterance (a truly counterfactual scenario which requires the use of a two-layered past perfect in other languages) and when the hypothesis concerns a more or less unlikely state of affairs in the present/future. The upshot of this is that the past tense morphology in counterfactuals is semantically empty or "fake"; its presence is "checked" not by the usual tense operator, but by an irrealis operator (cf. (3) above with the explicit irrealis marker "by" in Russian or the modal "would" in the English translation).

The issue of aspect is trickier from a cross-linguistic perspective. In this respect, it is interesting to compare Russian with Romance languages like French, where past tenses are inherently aspectual and counterfactuals are characterized by a strong preference for the imperfective version of the past tense (Imparfait in French). Here are two standard examples from French chess annotations. ${ }^{3}$

(4) Si les blancs jouaient ${ }^{[\text {ipf, past] }}$ simplement au premier coup "Cc3" suivi de "Cb1", les blancs se retrouveraient ${ }^{\left[{ }^{[c o n d i t i o n n e l]}\right.}$ alors dans la position initiale.

\footnotetext{
${ }^{2}$ This terminology alludes to feature checking mechanisms at the syntax-semantics interface in current versions of Minimalism, as in Grønn \& von Stechow 2008.

${ }^{3}$ Unless otherwise indicated the examples below are all found on the internet.
} 
If white in the first move simply played Nc3 followed by Nb1, then white would be back in the initial position.

(5) Si les noirs avaient ${ }^{[\text {[aux, ipf, past] }}$ joué $28 \ldots$ Fh8, les blancs auraient ${ }^{[\text {[aux, conditionnel] }}$ gagné en jouant 29. Ce7.

If black had played 28...Bh8, white would have won by playing 29. Ne7.

In the antecedent, French makes use of a simple imperfective past ("jouaient" in (4)) when the hypothesis is non-past or, as in (5), a past perfect with an imperfective past auxiliary (“avaient”) and a past participle (“joué") when the hypothesis is located in the past. In the consequent, the main verb in (4) and the auxiliary in (5) display so-called "conditional mood", which can be decomposed morphologically into an imperfective past tense ("-aient") and a future tense ("retrouver-" and "aur-", respectively). Russian appears not to overtly make the distinction between (4) and (5), but typically uses the perfective aspect, the subjunctive particle "by" and the past tense in both circumstances, as in the following example:

(6) Если бы белые сыграли ${ }^{[\mathrm{pf}, \text { past] } 3 . \mathrm{d} 4 \text { вместо 3.Kf3, то сейчас на доске возникла }}{ }^{[\mathrm{pf} \text {, }}$ past] бы популярная система Капабланки. If white played 3.d4 instead of 3.Nf3, then the popular Capablanca system would now appear on the board.

As stated above, the past tense ("-l" in Russian and "-ait" in French) is used universally in counterfactuals. When comparing the two languages, the following point must be stressed: in French the imperfective is a past tense, while in Russian, tense is morphologically independent from aspect. It is thus conceivable that the French imperfective past is used in 
counterfactual constructions for reasons not having to do with aspect (imperfectivity) as such, if it can be shown that the other aspectually loaded past tenses (passé simple and passé composé) are blocked in this grammatical environment. In Russian, the case is different inasmuch as the choice of past tense is not connected to the aspectual choice. For instance, in examples like (6), we have a complete event interpretation which "normally" triggers the perfective aspect.

Indeed, when the context favours true imperfective interpretations (progressivity, habituality/iterativity etc.), the imperfective is used within the counterfactual conditional in Russian:

(7) Ведь как россиянин, я был ${ }^{[i p f, \text { past] }}$ бы рад, если бы Крамник действительно был ${ }^{\text {[ipf, }}$ ${ }_{\text {past] }}^{\text {силен, выигрывал }{ }^{[i p f, ~ p a s t] ~} б ы ~ т у р н и р ы . ~}$

As a Russian I would be happy if Kramnik really played well and won tournaments.

In (7), Ipf is used because the sentence reports an iteration of hypothetical events (cf. the atelic VP: "to win matches"). This is in accordance with the accepted view that Ipf encodes either progressivity or habitual-iterative readings.

Also noteworthy is the obligatory use of the subjunctive particle "by" both in the antecedent and consequent in Russian counterfactuals. For each verb occurring in a counterfactual environment, there is a corresponding occurrence of the particle (cf. example (7) with 3 verbs and 3 occurrences of "by"). This represents in fact a kind of sequence of mood, since subsequent occurrences of the "by" particle do not involve a semantic world-shift relative to the updated counterfactual context, but merely "agree" with the first world-shift in the sentence. In Grønn \& von Stechow 2008 it is argued that all instances of "by" are checked 
and thus deleted in the semantic derivation by a covert counterfactual operator via multiple agreement.

\section{In the mood for chess}

With these considerations in mind, let us go back to our original Russian chess data, where this modal interpretation of the imperfective is not a marginal phenomenon, but indeed highly frequent. In fact, the expected combination " $\mathrm{Pf}+\mathrm{by}+$ past" is clearly blocked for Russian chess players in most cases. Here are some authentic examples from the web:

(8) 20.hxg5 В варианте 20.Kxg5? Cg4! белые немедленно теряли ${ }^{\text {[ipf, past] }}$ ферзя.

20.hxg5 In the line 20.Nxg5? Bg4! white would immediately have lost the queen.

(9) 32.a3 на 32.Лg3 следовало ${ }^{[\text {ipf, past] } 32 . . . h 5 !}$

32.a3 On 32.Rg3 there would have followed $32 \ldots h 5$ !

In the examples above a notational convention clearly distinguishes between actual (bold face) and hypothetical moves. However, even a reader who is not well informed concerning the game being analyzed will conclude from the use of the imperfective that the move under discussion was not actually played:

(10) Сразу решало ${ }^{[\mathrm{ipf}, \text { past] }}$ партию 22.Фb3.

22.Qb3 would immediately have decided the outcome of the game.

Another point worth noting is that certain temporal elements which normally trigger Pf do not seem to play any role here. For instance, the counterfactual Ipf co-occurs happily with 
punctual and future-oriented temporal adverbials (cf. "nemedlenno" in (8) and "srazu" in (10), both meaning "immediately").

There are also cases where the "antecedent event" is not an explicitly mentioned hypothetical chess move, as in the following example, where "inače - otherwise" points to an alternative course of events where the white player had overlooked black's 30th move.

(11) В этот момент необходимо было ${ }^{[\mathrm{ipf}, \text { past] }}$ увидеть 30-й ход, иначе белые проигрывали ${ }^{\text {[ipf, past] }}$.

At this point it was necessary to foresee move 30, otherwise white would have lost.

The contrast between the counterfactual Ipf and the "factual" Pf is particularly clear in examples like (12), where one of the players talks to a journalist about a finished game:

(12) В один момент я пошел ${ }^{[\mathrm{pf}, \text { past] }}$ Кe6-f4. Партия закончилась ${ }^{[\mathrm{pf}, \text { past] }}$ вничью. А после

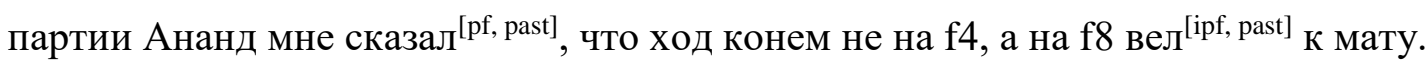
Вот если бы я так пошел ${ }^{[p f, p a s t]} . .$. Была ${ }^{[i p f, \text { past] }}$ бы красивая игра. Ананд был ${ }^{[i p f, \text { past] }}$ прав: выигрывало ${ }^{[\mathrm{ipf}, \text { past] }} 51 . \mathrm{Kf} 8$ !

At one moment I went Ne6-f4. The game ended in a draw. But after the game Anand told me that moving the knight not to f4, but to f8 would have led to mate. If I had played like that ... that would have been a nice game. Anand was right: 51.Nf8! would have won.

Interestingly, we observe a structural movement towards a harmony of forms, such that imperfective verbs with a counterfactual interpretation often succeed each other. In fact, my 
informants find all alternative forms to be ungrammatical or infelicitous in this environment, cf. the following cases:

Путем 50...Са4! и затем Сc2 черные выигрывали ${ }^{\text {[ipf, past] }}$ ладью и побеждали ${ }^{\text {[ipf, past] }}$ (\#pobedili; ??pobedili by; ??pobeždali by).

After 50...Ba4! followed by Bc2 black would have won a rook and the game.

(14) Брать на g5 было ${ }^{[\mathrm{ipf}, \text { past] }}$, конечно, нехорошо, так как в игру включался ${ }^{[\mathrm{ipf}, \text { past] }}$ черный ферзь, и белые сразу же попадали ${ }^{[\mathrm{ipf}, \text { past] }}$ (\#popali; ??popali by; ??popadali bу) под сильнейшую атаку.

To take on g5 would, of course, have been bad, since the black queen would have become activated, and white would immediately have been put under heavy pressure.

Examples (13) and (14) are characterized by what can be called "sequence of mood" (from the point of view of the irrealis interpretation of the verbs) or "sequence of aspect" (from the morphological point of view: imperfective aspect). These data seem to indicate that Russian, which is not a sequence of tense language (Russian typically has relative tenses), exhibits a sequence of mood both with "by" and the counterfactual Ipf.

Judging by the examples above, the sequence of mood effect appears to be similar to what is known in dynamic semantics as intersententional "modal subordination"4. However, this is not so, since the structural harmony of imperfectives without subjunctive marking does not extend beyond sentence boundaries. Example (15) below shows that the phenomenon under discussion is closer to intrasentential "multiple agree":

\footnotetext{
${ }^{4}$ A standard example of this phenomenon is the following:

(i) A wolf might come in. It would (\#will) eat you first.
} 
(15) 21...Сg5? После 21...exf5 22.Лxd5 Сxd6 23.exd6 Лfe8+ 24.Кpd1 Фd7 25.Фxf5 Ле6

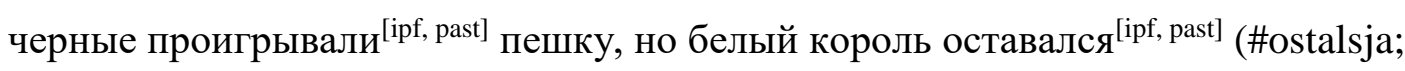
??ostalsja by; ??ostavalsja by) в центре при наличии на доске всех тяжелых фигур. К тому же пешка d6 не могла ${ }^{[i p f, \text { past] }}$ бы (??mogla) чувствовать себя в полной безопасности.

21...Bg5? After 21...exf5 22.Rxd5 Bxd6 23.exd6 Rfe8+ 24.Kd1 Qd7 25.Qxf5 Re6 black would have lost a pawn, but the white king would have been stuck in the centre with all the heavy pieces left on the board. Furthermore, the pawn on d6 would not have been entirely in safety.

The list of examples with the counterfactual Ipf in chess annotations can easily be extended. The truth-conditions of these sentences do not to differ from what we observed with "Pf + by" in (3/3'), Ipf apparently being a free variant of "by + Pf" in this environment. In other words, in the most similar worlds in which "white plays 51.Nf8!, white wins" (example 12).

The point where the hypothetical chess move departs from our world (the actual game) is typically designated not by a full-fledged if-clause, as in standard counterfactual conditionals from section 2, but by the alternative move itself or a prepositional phrase, e.g. "posle ...after + chess move", "putem - by + chess move", "pri - by + chess move" etc.

These data do not prove, however, that a "normal" subjunctive if-clause antecedent in this construction is unavailable. If the hypothetical move is indeed given by a finite if-clause, the irrealis marker "by" has to be used in the antecedent (but not in the consequent!), cf. (16).

(16) Если бы белые сыграли ${ }^{[\mathrm{pf}, \text { past] }} 27 . \Phi \mathrm{6} 6+$, то ход 29...Лf7 сразу проигрывал ${ }^{\text {[ipf, past] }}$. 
If white had played 27.Qh6+, then the move 29...Rf7 would have lost immediately.

Note that with the presence of the irrealis marker "by" in the if-clause, the verb in the antecedent is perfective. Thus the counterfactual Ipf is clearly a main-clause phenomenon. In this respect, the Russian construction seems to differ decisively from the standard French examples above which were characterized by the use of the imperfective aspect in the antecedent.

\section{Approaching the middle game: Two imperfect hypotheses about hypothetical imperfectivity}

One might think that the phenomenon under discussion is merely a Russian (Slavic) quirk, but then examples like these from French are puzzling:

(17) 12.Fxc7 Virtual accepte ${ }^{[\text {present] }}$ les complications, car après le retrait du Fou en h4, les Noirs jouaient ${ }^{[i p f, \text { past] }}$ f6 avec une position préférable.

12.Bxc7 Virtual accepts complications, since after the retreat of the bishop to h4, black would have played f6 with the advantage.

(18) Si les noirs avaient ${ }^{\text {[aux, ipf, past] }}$ joué $21 . .$. Dh4+, les blancs répliquaient ${ }^{\text {[ipf, past] }}$ par Th2! If black had played $21 \ldots$ Qh4+, white would have responded by $R h 2$ !

This is not quite the usual pattern used in French counterfactuals where one expects only the antecedent to exhibit plain imperfective morphology and the consequent to make use of conditional mood (imperfective + future). The cross-linguistic parallels in (8)-(18) beg the 
question: Is the counterfactual Ipf in Russian derivable from some universal concept of imperfectivity?

Imperfectivity is cross-linguistically (e.g. in Slavic and Romance) associated with progressivity and habituality, and it is therefore natural to ask whether this modal, counterfactual Ipf can be subsumed under progressivity and/or habituality.

\subsection{Counterfactual Ipf and progressivity}

The progressive reading of the imperfective gives rise to the famous imperfective paradox:

В минувшую пятницу около 23.00 местного времени хоккеист переходил ${ }^{[i p f, \text { past] }}$ улицу, когда поблизости произошло ${ }^{[\mathrm{pf}, \text { past] }}$ столкновение двух машин. Одна из них сбила ${ }^{\left[p f, p^{p a s t]}\right.}$ игрока.

Last Friday at about 23.00 local time, the hockey player was crossing the street when an accident between two cars happened. One of the cars hit the player.

The paradox is illustrated here in a context where the ongoing event of crossing the street is actually interrupted and thus never reaches its inherent culmination. On what grounds is the speaker justified in using a telic predicate $P$ (here: "to cross the street" in the imperfective aspect) when there is no corresponding complete (completed) event of type $P$ in the actual world? The standard answer involves a modal component: A progressive imperfective of a predicate of events $P$ (here: "to cross the street") is true of a time $t$ (here: "last Friday at about 11 p.m."), if an event $e^{\prime}$, which is a sub-event of an event $e$ of type $P$, holds at $t$, and in all stereotypical (normal) continuation worlds $w$ in which no exterior interruption event occurs, an event $e$ is true in $w$ at some time $t^{\prime}>t$. 
This implies that a complete event of the type of the telic predicate need not occur in the actual world (the course of events may be interrupted, as in the scenario in (19)), but it must occur in all stereotypical/normal continuations where there is no interruption.

So both the progressive and counterfactual imperfective involve reference to a complete event in accessible possible worlds, without making any claim concerning the existence of such an event in the actual world. Nevertheless, this parallel with the modality of the progressive, which has been given a Kratzerian treatment in (Portner 1998) ${ }^{5}$, is not quite what we are after, since the imperfective in (2) does not exhibit a fundamental property of the progressive; there is no reference to incomplete events (subevents) of winning in the actual world. In other words, while the progressive and counterfactual Ipf are similar with respect to the completion of the event taking place in the stereotypical inertia worlds, the difference concerns what is actually going on in the actual world. In the case of the counterfactual Ipf, the answer is nothing.

The difference between a truly progressive reading and the counterfactual Ipf is reflected in the temporal adverbials which provide the assertion time (reference time), i.e. the time interval of the speaker's focus. In (19), the assertion time ("last Friday at about 11 p.m.") can be conceived of as punctual and as such it can easily be included in the temporal span of the event, producing a progressive interpretation. On the contrary, in chess comments we typically encounter temporal adverbials like "after 22.e4", which denote a temporal interval starting with the chess move 22.e4 as its left boundary. In the indicative mood with actual

\footnotetext{
${ }^{5}$ In the formal semantics literature, the most influential analysis of the progressive (in terms of "inertia" worlds, i.e. stereotypical continuations) goes back to Dowty 1979. At the same time, Kratzer's work exerts a huge impact on formal approaches to modality (including counterfactual conditionals). Portner brings these two approaches together in his analysis of the English progressive.
} 
chess moves and perfective VPs, the right boundary of this interval is restricted by the past tense; hence the assertion time is the interval stretching from the move $22 . \mathrm{e} 4$ to the time of utterance. Clearly, this interval - due to its length - cannot be included in the time span of, say, an event such as white winning. We thus end up with the "perfective" complete event interpretation, where the event time is included in the assertion time. A similar, "perfective" temporal relationship is also true for the counterfactual Ipf, the only difference in temporality being that the right boundary of the assertion time "after 22.e4" is perhaps best thought of as being open to the infinite future (not restricted by past tense as it is normally).

\subsection{Counterfactual Ipf and habituality}

There is also a cross-linguistic link between habituality (or iterativity) and counterfactuality. One language where this correlation is prominent is Hindi, where a habitual participle marks counterfactual environments (McCready \& Reese 2002). Unlike the English “would”, the Hindi habitual participle requires overt morpho-syntactic licensing (e.g. an if-clause) to convey counterfactuality. Also in the case of the Russian counterfactual Ipf, the interpretation must of course be licensed by elements in the context, e.g. hypothetical chess moves.

What does habituality and counterfactuality have in common? The obvious place to look is in the quantificational structure of the construction $(P$ is a predicate morphologically marked for habituality/counterfactuality): "For each stereotypical situation $s \ldots$ there is an event $e$ of type $P$ which is true in $s \ldots$ " (habituality) vs. "For each stereotypical world $w \ldots$ there is an event $e$ of type $P$ which is true in $w \ldots$ ". (counterfactuality). For reasons that will soon become clear, I see no point of trying to spell out this analogy in any detail. 
Interestingly, a habitual-iterative interpretation can co-occur with the "bare" counterfactual Ipf, i.e. without an explicit "by":

(20) Гата играет с повышенным запасом прочности. К примеру, в его распоряжении были ${ }^{[i p f, \text { past] }}$ заманчивые возможности выиграть пешку d4, но при этом черные получали ${ }^{[\text {ipf, past] }}$ фигурную контригру.

Gata plays with an extra portion of solidity. For instance, at his disposal were various tempting possibilities to win the pawn on $d 4$, but in that case black would have gotten counter play with his active pieces.

In this case, the "covert antecedent" involves several hypothetical possibilities of winning the pawn on d4, each time resulting in black getting counter play. According to my informants, the alternative subjunctive imperfective form "polučali by" is much more acceptable here than substituting "Pf + by" for the cases of singular hypothetical events such as (8)-(16) above. The speaker seems to have a real choice in (20). She can use a bare imperfective to mark counterfactuality, which is what we observe in the authentic text, leaving the iterative interpretation unexpressed as such. Alternatively, the speaker can mark counterfactuality explicitly through the presence of the subjunctive "by", reserving the imperfective verb "polučali" for marking the iterative interpretation. In fact, this genuine option (according to informants) suggests that the difference between singularity and plurality of events does not to play any particular role for the counterfactual Ipf.

Nevertheless, a significant reason for rejecting a possible reduction of the counterfactual Ipf to imperfective core meanings, is the following: If the counterfactual Ipf is systematically associated with the presence of a semantic operator such as PROG or HAB, we then expect 
this option to be systematically available at the syntax-semantics interface of Russian. The next section shows that this is not the case.

\section{If language were more than a game}

Let us abandon the world of chess for a while and turn the board. Is the counterfactual Ipf productive or interpretable in Russian tout court? It turns out that it is quite difficult to find or even construct - examples of the counterfactual Ipf outside the domain of chess annotations. ${ }^{6}$ After some hesitation, my informants do accept a counterfactual interpretation of the imperfective in carefully constructed scenarios like (21) and (22) below, although they would hardly produce such sentences themselves:

(21) К счастью я не провалился ${ }^{[\mathrm{pf}, \text { past] }}$ на экзамене. После провала меня выгоняли ${ }^{[\mathrm{ipf} \text {, }}$ ${ }^{\text {past] }}$ из университета. (constructed example) Luckily, I did not fail the exam. In case of failure I would have been thrown out of the university.

(22) Пострадавший не дышал. Хорошо, что среди пассажиров оказался ${ }^{\text {[pf, past] }}$ врач, сразу приступивший к искусственному дыханию, без которого смерть наступала ${ }^{\text {[ipf, past] }}$ через считанные минуты. (constructed example)

The injured person didn't breathe. It was good that one of the passengers turned out to be a doctor who immediately started to give artificial breathing, without which death would have occurred within few minutes.

\footnotetext{
${ }^{6}$ True, I found some cases on the internet from annotations of games of draught, but the finer distinctions between chess and draught should not concern us here.
} 
The hearer is forced to make sense of the speaker's choice of Ipf in (21) and (22), and the counterfactual interpretation is indeed optimal since it is in fact the only available option for the hearer. What characterizes these contexts is the very explicit counterfactuality conveyed by elements independent of the verbal predicate itself. The context simply leaves no room for verb ambiguity: the imperfective must be interpreted counterfactually since the proposition in which Ipf occurs is contrary to the facts described in the preceding context. Furthermore, the punctual telic predicates in question do not allow for a progressive reading without special marking by adverbials etc. These factors explain why my informants are able to correctly interpret the sentences as referring to complete counterfactual events, although they are reluctant to actively produce this counterfactual Ipf themselves. The latter also has a natural explanation; the speaker indeed has the alternative option, which is clearly preferable, of using "Pf + by" (“vygnali by" and "nastupila by", respectively).

Interestingly, this is the point where Russian differs from French. In French, the bare imperfective (without the conditionne/morphology) has a productive counterfactual meaning. In (23), not only the antecedent, but also the consequent contains pure imperfective morphology.

(23) S' il était ${ }^{\text {[aux, ipf, past] }}$ arrivé hier soir, il voyait ${ }^{\text {[ipf, past] }}$ Marie. (Hacquard 2006, 84)

If he had arrived yesterday evening, he would have seen Marie.

The translation of this example into Russian reveals a completely different distribution of TAM morphology: 


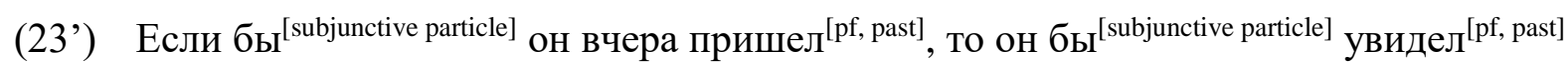
Машу. (\#on videl ${ }^{[i p f, \text { past] }}$ Mašu)

The data above suggests that the French imperfective past may be semantically related to counterfactuality, either by pointing to an irrealis operator - or indirectly through some possible relationship between counterfactuality and other core meanings of imperfectivity. ${ }^{7}$ However, for the Russian imperfective the same position is invalid since the restrictions on the counterfactual interpretation of Ipf (outside the sphere of chess annotations) are too strong. In Russian chess comments, we observe what Iatridou (2000) calls a “fake imperfective", that is an imperfective with a "perfective" (complete event) interpretation. A pragmatic - and not semantic - explanation of the Russian data will be provided in the next section.

\section{Return to competition - a game with two solutions}

The consequence of the last section is that there is no systematic operator associated with the Russian imperfective which triggers the counterfactual interpretation. If this were the case, then we would expect the operator to be available in canonical counterfactual contexts. This argument against a purely semantic explanation of the phenomena holds irrespective of whether we want to posit a "new" IRREALIS operator, or try to reduce the counterfactual Ipf to PROG or HAB. These approaches are all conceivable in isolation, but they fail to explain the restrictions. For instance, a semantic IRREALIS operator would of course be able to account for the observed data, but positing such an operator would grossly overgenerate.

\footnotetext{
${ }^{7}$ It is also conceivable that the French imperfective is a default past tense with no aspectual meaning in counterfactual constructions (Hacquard 2006). On this view, it is the past tense component of Imparfait which correlates with counterfactuality.
} 
In order to explain why Ipf develops a counterfactual reading in certain specific contexts, I will invoke a pragmatic explanation related to context-sensitive and non-compositional competition between form-meaning pairs along the lines of Bidirectional Optimality Theory (Blutner 2000) and (Grønn 2008). BiOT provides us with a formally precise framework for pragmatic reasoning and incorporates both the speaker and hearer perspective simultaneously, hence "bidirectionality".

The discourse context in the case of chess annotations is particularly transparent, without any "noise" such as covert reference times which could pull the imperfective in different directions. This transparency is important in order to arrive at a disambiguation of Ipf. What is furthermore special about chess annotations is the clear-cut separation of worlds: the actual world and the hypothetical worlds. This provides us with a division between two disjunctive meanings, ideally suited for the inventory of aspectual forms in Russian. These factors all contribute to making chess annotations an ideal environment for a new aspectual convention to emerge.

In fact, it is not difficult to explain why Ipf and not Pf is used with a counterfactual interpretation, since Pf already has an optimal interpretation denoting factual events. The obvious and more serious competitor for counterfactual Ipf is the form "Pf + by", but then it can be argued that the bare Ipf is less complex, hence a more economic form. The idea is therefore that if the simple form of Ipf can be used unambiguously in a counterfactual context, there is no need for the speaker to use the more complex "Pf + by". 8

\footnotetext{
${ }^{8}$ The picture changes somewhat when we consider the impact of tense towards the end of the paper.
} 
Although it is reasonable to ignore progressive and habitual-iterative interpretations in our cases, we cannot a priori leave out the possibility of the imperfective having a purely factual interpretation, i.e. referring to actual moves or outcomes in the game. Since we reject the idea of associating Ipf with a semantic irrealis operator, it would be completely ad hoc to rule out the factual interpretation a priori. The imperfective is truly underspecified, thus in principle compatible with both factual and counterfactual interpretations. ${ }^{9}$

In the BiOT tableau below, the set of possible contents is contextually restricted to complete events in the world of evaluation (=actual outcome) and complete events in possible worlds (=hypothetical outcome).

Table 1: BiOT tableau with initial assignment of conditional informativity

\begin{tabular}{|c|c|c|}
\hline Conditional informativity & actual outcome & hypothetical outcome \\
\hline Pf + past & 1 & \\
\hline Ipf + past & 0.6 & 0.4 \\
\hline Pf + by & & $1-\mathrm{c}$ \\
\hline Ipf + by & & $1-\mathrm{c}$ \\
\hline
\end{tabular}

The BiOT reasoning involves a comparison of all relevant form-meaning pairs generated by the grammar. For a form-meaning pair to survive, it is generally best to score high in terms of "conditional informativity". Leaving formal rigor aside, the intended reading of the tableau is explained below.

\footnotetext{
${ }^{9}$ See Grønn \& Krave 2007 for more on the former interpretation of Ipf.
} 
I assume here that the forms Pf and Ipf are equally complex, while the presence of the subjunctive particle "by" violates speaker economy (cf. the markedness constraint "avoid complexity of form"). In the metric used here, complex forms are penalized by reducing the conditional informativity value with the constant "c", which represents a relatively large number (e.g. >0.6).

It is mutual knowledge between the speaker and hearer that conveying the actual moves being played and the actual outcome of the game is the first priority. Concerning the two disjunct contents "actual outcome" and "hypothetical outcome", the latter is therefore ranked below the former in terms of stereotypicality. We can assume that it is easier for the hearer to interpret an utterance stereotypically or harmonically, and thus the mutual goal of successful communication enhances stereotypical interpretations.

The idea behind the measurement provided by "conditional informativity" is in a nut shell the following: The probability of the form "Pf + past" having the interpretation of "actual outcome" is 1 , that being the maximum score. If the speaker chooses "Pf + past", there is no chance of miscommunication, since the hearer will always interpret "Pf + past" as the speaker-intended meaning "actual outcome". Hence this form-meaning pair is clearly optimal in both directions ("horizontally" for the hearer and "vertically" for the speaker in the tableaux).

The bare imperfective is semantically underspecified and compatible with both meanings. Since actual chess moves are more stereotypical than hypothetical moves in chess annotations, the probability of "Ipf + past" referring to an actual outcome is in fact slightly higher than the probability of it referring to a hypothetical outcome. Still we have to explain 
why the form-content pair <Ipf + past, actual outcome $>$ is blocked, while <Ipf + past, hypothetical outcome > is bidirectionally optimal.

To this end, we use the following algorithm provided by Blutner's so-called weak BiOT (here presented informally):

(1) We start with the candidate $<\mathrm{Pf}+$ past, actual outcome $>$, which is clearly optimal (M) in both directions (horizontally and vertically). All pairs which are beaten by an optimal pair in one direction are crossed out and removed from the tableau, producing table 2.

Table 2: BiOT tableau with one optimal form-meaning pair

\begin{tabular}{|c|c|c|}
\hline Conditional informativity & actual outcome & hypothetical outcome \\
\hline Pf + past & M1 & \\
\hline Ipf + past & 0.6 & 0.4 \\
\hline Pf + by & & $1-\mathrm{c}$ \\
\hline Ipf + by & & $1-\mathrm{c}$ \\
\hline
\end{tabular}

(2) We repeat the search for a weakly optimal pair among the remaining candidates which were neither blocked nor optimal in the first round.

(3) If complexity of form - the cost value - is taken to be sufficiently high, i.e. $>0.6$, the pair $<$ Ipf + past, hypothetical outcome $>$ emerges as a winner from the perspective of weakly bidirectional optimization, as in table 3. Accordingly, the forms "Pf + by" and "Ipf + by" with the interpretation of hypothetical outcome are blocked by this weakly 
optimal pair (cf. step 1 above). The algorithm ends since there are no further formcontent pairs to consider.

Table 3: BiOT tableau with two (weakly) optimal form-meaning pairs

\begin{tabular}{|c|c|c|}
\hline Conditional informativity & actual outcome & hypothetical outcome \\
\hline Pf + past & M1 & \\
\hline Ipf + past & 0.6 & M0.4 \\
\hline Pf + by & & $1-\mathrm{c}$ \\
\hline Ipf + by & & $1-\mathrm{c}$ \\
\hline
\end{tabular}

The results of this form-meaning optimization is a pragmatic strengthening of Ipf as referring to hypothetical outcomes (the counterfactual interpretation), thus correctly predicted by Weak Bidirectional OT (given some reasonable assumptions).

\section{Structural pressure and the counter attack of "by"}

In the previous section, we started out with four different forms and two disjunctive contents, and ended up with two winning combinations $<\mathrm{Pf}+$ past, actual outcome $>$ and $<\mathrm{Ipf}+$ past, hypothetical outcome $>$. The rational optimization procedure in the tableaux above left no room for complex forms such as "Pf + by" and "Ipf + by". However, these losing forms can still reappear on the board if we slightly alter the linguistic context or consider a more subtle division of the set of contents. 


\section{1 "Pf + by"}

Let us start with "Pf + by", observed in example (24):

Сыграв $^{[\mathrm{pf}, \text { gerund] }} 6 . . . \mathrm{e} 4 ?$, чёрные допустили ${ }^{[\mathrm{pf}, \text { past] }}$ бы промежуточный ход 7.Cd5, после чего белые получали ${ }^{[\mathrm{ipf}, \text { past] }}$ заметное позиционное преимущество. By playing 6...e4?, black would have allowed for the intermediate move 7.Bd5, after which white would have gained a clear positional advantage.

Note that the hypothetical move in this case occurs in a reduced antecedent consisting of a non-finite gerund, which requires the perfective aspect, but not the presence of "by". The explanation for the use of Pf in the main clause ("dopustili by") is therefore related to a kind of structural harmony between the two perfective verbs ("sygrat"' and "dopustit"'). By choosing "Pf + by", the speaker highlights the temporal relationship between the two hypothetical events ("sygrav... dopustili"), which is similar to the phenomenon of narrative progression, characteristic of $\mathrm{Pf} .{ }^{10}$ In the setting of BiOT, this pressure towards structural harmony ("Pf_1...Pf_2") could reduce the penalty ("c") assigned to "Pf + by" above, thus allowing for "Pf + by" to beat its main competitor, the bare imperfective, or we could add more candidate contents to the tableau (see section 9 below).

However, my informants in fact accept the bare Ipf "dopuskali - allowed" as equally good in the context of (24). How do we explain this alternation? The point is that the imperfective "polučali - gained" in the final clause of (24) favours the use of "dopuskali" in the intermediate clause in order to arrive at a structurally harmonic "sequence of mood/aspect". In

\footnotetext{
${ }^{10} \mathrm{Pf}$, unlike the possibly "fake" Ipf, always retains its invariant meaning, also in combination with "by".
} 
summary, example (24) represents a linguistic context with truly conflicting interests pulling in different directions.

Our theory also predicts that "Pf + by" is preferred whenever there is a possibility (perhaps due to accommodation) that the bare Ipf could be interpreted with a processual/progressive meaning. This leads us to a different set of contexts than the ones we have encountered so far.

\subsection{Progressivity, after all}

There is no way of expressing a progressive, hypothetical interpretation in the contexts considered in section 6 , where we only considered complete events (actual/hypothetical "outcomes"). A crucial prerequisite for the counterfactual Ipf is precisely the unavailability of the progressive interpretation. This assumption is reasonable given the nature of chess annotations but can also be linguistically motivated.

Semantically speaking, the progressive interpretation in a modal context is very close to a modal complete event interpretation. Similarly in English, where the imperfective is unambiguously progressive, counterfactual expressions like "white would win after ..." and "white would be winning after..." are practically synonymous. The point here is that the modal component of progressivity ("white wins in the inertia worlds") equals the counterfactual complete event interpretation "white wins in the most similar worlds" and is practically indistinguishable also from the "counterfactual progressive" ("vyigryvali by") "white is in the process of winning in the most similar worlds, a process which inertially will lead to an event of white winning the game". Thus, in general, only two forms and two 
meanings are actually worth expressing/denoting: Pf with an actuality entailment and Ipf with a counterfactual interpretation. ${ }^{11}$

Nevertheless, in the authentic example below, we do actually find the form-meaning pair <Ipf + by, hypothetical process $>$.

(25) На 6...Фхd5 белые выигрывали ${ }^{[\mathrm{ipf}, \text { past] }}$ бы фигуру, продолжая ${ }^{[\mathrm{ipf}, \text { gerund] }} 7 . \mathrm{b} 4$ Фxd4 (7...Фxg2 8.Ce4) 8.Kge2.

On 6...Qxd5 white would have been winning a piece, by continuing 7.b4 Qxd4 (7...Qxg2 8.Be4) 8.Nge2.

However, this example arguably represents a different kind of context due to the presence of the imperfective gerund "prodolžaja" which favours some kind of "harmonic agreement" between imperfective verbs. In this light, the imperfective "vyigryvali" is no longer "fake" since it echoes an imperfective gerund in the neighbouring clause. Accordingly, "by" is needed to mark irrealis and the imperfective verb retains its normal (processual) meaning. This kind of reasoning is the same as we applied in connection with example (20) above and the possibility of using "Ipf + by" in order to convey a truly iterative-counterfactual interpretation.

\footnotetext{
${ }^{11}$ This is not to deny the possibility of "indicative" progressive winning events. However, if the speaker really wants to convey the coercion of a predicate into a progressive actual world winning event, she cannot simply use the bare imperfective ("vyigryvali"), but needs to invoke additional cues such as "progressive triggering" temporal adverbials, thus leading the hearer into another context (and a different BiOT-tableau).
} 


\section{The end game: What about past tense?}

Restan (1989) claims that the past tense morphology in the counterfactual Ipf construction corresponds to a semantic past; this issue is far from trivial. Grønn (2006) explores the possibility of treating past tense as semantically empty, being checked by an abstract (possibly covert) irrealis operator in the same way as the operator associated with "by" “checks and deletes" past tense morphology in normal counterfactuals. This irrealis operator must be distinct from the aspectual operator. The imperfective morphology is presumably checked by a "fake", default aspectual operator. But if this is correct, then it would be unreasonable to let another "real" aspectual (imperfective) operator be responsible for the checking of past tense morphology (cf. also section 6 above).

The question which I will address in this section is the following: Is the past tense in counterfactual Ipf semantically empty to the same extent as past tense in normal counterfactual conditionals? The following example suggests that this is the case.

(26) Приходится брать ферзем, поскольку при 28...gh 29.Ле6 черные проигрывали ${ }^{\text {[ipf, }}$ past] cpa3y.

Black has to capture with the queen since after 28...gh 29.Re6 black would have lost right away.

My informants also accept the use of present tense in (26): "proigryvajut". This, however, does not mean that "proigryvali" is felicitous in contexts which require a semantic non-past (present or future) interpretation. The point is that the present tense in (26), "prichoditsja", is not a "real" present, but some kind of historical present (or present of report). Hence, all we 
can conclude from (26) is that the counterfactual Ipf can co-occur with the historical present, which may still imply some reference to a semantic past.

In the previous accounts of this phenomenon - Restan 1989 and Grønn 2006 - there were no diagnostics used to decide the issue of tense interpretation. However, online annotations of chess games on the internet provide us with a good test case. Consider for instance the following example, where the annotator, waiting for the white player to make his $21^{\text {st }}$ move, discusses possible continuations from the actual position after black's $20^{\text {th }}$ move. The speaker (annotator) thus does not know which move will eventually be played:

(27) 20.Bхе5 Фd7. Логичный позиционный ход. У меня есть подозрение, что в случае 21.Кd2 черные достигают ${ }^{[i p f, \text { present] }}$ (\#dostigali) ничьей простым переходом в "разноцвет".

20.Bxe4 Qd7. A logical positional move. I suspect that in case of 21.Nd2 black achieves a draw by a simple transposition into an opposite-coloured bishops endgame.

In (27), the speaker's choice of present tense is not interchangeable with the counterfactual Ipf, but is this due to temporal semantics or lack of counterfactuality in (27)? Finally, the following example, also from online annotations, seems to decide the issue in favour of Restan's original claim:

(28) 41.Ла4 А это похоже на зевок фигуры... Правда, черным предстоит найти этюдный вариант. 41...Сc6! 42.Лха7 Ле1! Важнейший промежуточный шах. 43.Кpf2 Ле7 44.g4 При короле на g1 это выручило ${ }^{[p f, p a s t]}$ бы (\#vyručalo) белых. 
44...fxg4 45.Ла5 Кpf4, и шахов больше нет. Висит конь, а также грозит g4-g3+ c матом.

41.Ra4 But this looks like a blunder of a piece... True, black has to find a study like continuation. 41 ...Bc6! 42.Rxa7 Re1! An important intermediate check. 43.Kf2 Re7 44.g4 With the king on g1 this would have saved white. 44...fxg4 45.Ra5 Kf4, and there are no more checks. The knight is hanging, and there is also the threat of $g 4-g 3+$ with mate.

The counterfactual hypothesis in connection with white's move 44 is clearly located in the future, hence the speaker's choice of "Pf + by" and a semantically empty past tense. Importantly, my informants do not accept a bare counterfactual Ipf and past tense in this environment.

Not surprisingly then, our constructed and somewhat unnatural examples outside the sphere of chess annotations (cf. (21) above) become simply ungrammatical when the counterfactual hypothesis is non-past:

(29) А: Экзамен отменен!

В: Какое облегчение! В случае провала меня выгнали ${ }^{[\mathrm{pf}, \text { past] }}$ бы (\#vygonjali) из университета. (constructed example)

A: The exam is cancelled!

B: What a relief! In case of failure I would have been thrown out of the university.

In the final section, I will briefly demonstrate how this difference in tense interpretation between counterfactual Ipf and "Pf + by" gives rise to further pragmatic strengthening. 


\section{Putting the pieces together}

It is time to have a larger overview of the game played in the previous sections as well as to speculate somewhat on the next few moves ahead.

In this paper I have tried to explain a peculiar use of the imperfective in Russian as a case of pragmatic strengthening in Bidirectional Optimality Theory. The construction in question here labelled counterfactual Ipf - is rather marginal, and typically restricted to chess annotations (albeit highly frequent in this environment). However, the importance of this phenomenon is related to more general properties of form-meaning optimization and aspectual competition. The counterfactual Ipf illustrates the potential of the underspecified imperfective, and we can assume that other pragmatic and discourse-sensitive implicatures associated with Ipf in Russian also arise as a result of competition with Pf (see Grønn 2008 for examples and a BiOT-analysis). The semantically invariant Pf is optimal in denoting stereotypical complete events, but this opens for the possibility of Ipf fighting back and gaining new territory by seeking non-stereotypical complete event interpretations, such as counterfactual outcomes of chess games.

The discussion of the data suggests, in fact, two rounds of optimization. First, Ipf is associated with counterfactual events in competition with the factual event interpretation of Pf. Apparently, there is no room for the complex form "Pf + by" in this picture. However, a more subtle analysis of the role of the past tense (section 8) reveals a second division of pragmatic labour; cf. the BiOT tableau in table 4.

Table 4: BiOT tableau with different TAM-combinations (the cost value " $\mathrm{c}$ " is $>0.2$ ) 


\begin{tabular}{|c|c|c|c|}
\hline Conditional & $\begin{array}{c}\text { actual } \\
\text { informativity }\end{array}$ & $\begin{array}{c}\text { hypothetical outcome } \\
\text { outcome }\end{array}$ & $\begin{array}{c}\text { hypothetical outcome in the } \\
\text { present/future }\end{array}$ \\
\hline $\mathrm{Pf}+$ past & $\mathrm{M} 1$ & & \\
\hline $\mathrm{Ipf}+$ past & 0.6 & $\mathrm{M} 0.4$ & $\mathrm{M} 0.5-\mathrm{c}$ \\
\hline $\mathrm{Pf}+\mathrm{by}$ & & $0.5-\mathrm{c}$ & \\
\hline
\end{tabular}

The bare Ipf in combination with past tense morphology is not compatible with hypothetical states of affairs in the present/future, while the past tense is semantically empty in the presence of "by". This finally explains why "Pf + by + past" is judged to be slightly infelicitous by my informants in chess annotations of finished games; in accordance with the principles of conditional informativity there is a preference for the more restricted and "stronger" counterfactual Ipf. However, when the hypothesis is non-past (e.g. in examples (6) and (28)), the more flexible - in terms of tense interpretation - combination "Pf + by + past" is the optimal candidate after all.

The counterfactual Ipf, being restricted to chess annotations, thus highlights the contextsensitivity of imperfective readings. At the same time it provides an interesting case of noncompositionality, since tense seems to play a role in the aspectual choice. All this together points to the need for a purely pragmatic explanation of the phenomenon.

Could the counterfactual Ipf in Russian become more frequent and eventually be conventionalized in other, more familiar discourse contexts? Yes, in principle, but it appears that ordinary discourse contains too much "noise" in order for the speaker and hearer to tacitly agree on the set of competing candidate forms and contents required for the counterfactual Ipf 
to emerge as a winner. Hence, the speaker is normally obliged to use a more complex, but unambiguous construction involving the particle "by".

\section{References}

Blutner, Reinhard. 2000. "Some aspects of optimality in natural language interpretation". Journal of Semantics 17, no. 3:189-216.

Dowty, David. 1979. Word Meaning and Montague Grammar. The Semantics of Verbs and Times in Generative Semantics and in Montague 's PTQ. Dordrecht: Reidel.

Grønn, Atle. 2006. "Irrealis and sequence of TAM". In Proceedings of the Workshop on Concord and the Syntax Semantics Interface. Edited by P. Dekker and H. Zeijlstra. ESSLLI workshop: Malaga 2006.

Grønn, Atle. 2008. "Russian Aspect as Bidirectional Optimization". In Studies in Formal Slavic Linguistics. Linguistik International, vol. 19, edited by F. Marušič and R. Žaucer. Frankfurt am Main: Peter Lang.

Grønn, A. and M. F. Krave. 2007. "Konkurencija vidov: pragmatičeskie implikatury i anaforičeskie presuppozicii nesoveršennogo vida". Voprosy jazykoznanija 4:51-63.

Grønn, A. and A. von Stechow. 2008. Tense and Presuppositions in Counterfactuals. manuscript.

Hacquard, Valentine. 2006. Aspects of Modality. PhD thesis, MIT. 
Iatridou, Sabine. 2000. "The Grammatical Ingredients of Counterfactuality", Linguistic Inquiry 31, no. 2:231-270.

Klein, Wolfgang. 1995. "A Time Relational Analysis of Russian Aspect". Language 71:669695.

McCready, E. and B. Reese. 2002. "Counterfactual Morphology and the Licensing of Modal Subordination in Hindi". Presented at South Asian Languages Analysis Roundtable XXII. University of Iowa.

Portner, Paul. 1998. "The Progressive in Modal Semantics". Language 74:760-787.

Restan, Per. 1989. "Ne bylo, no moglo by byt’: O gipotetičeskoj modal'nosti". ScandoSlavica 35:203-210. 